BULLETIN Bulletin hispanique

HispaniQuE Université Michel de Montaigne Bordeaux

116-2 | 2014

Référentialité/autoréférentialité dans le roman

espagnol contemporain : bilan et perspectives

\title{
Incursiones en los Alrededores de Álvaro Pombo
}

Irène Andres-Suárez

\section{(2) OpenEdition \\ Journals}

Edición electrónica

URL: https://journals.openedition.org/bulletinhispanique/3446

DOI: 10.4000/bulletinhispanique.3446

ISBN: 979-10-300-0156-3

ISSN: $1775-3821$

Editor

Presses universitaires de Bordeaux

Edición impresa

Fecha de publicación: 1 diciembre 2014

Paginación: 625-641

ISBN: 978-2-86781-963-6

ISSN: 0007-4640

\section{Referencia electrónica}

Irène Andres-Suárez, «Incursiones en los Alrededores de Álvaro Pombo», Bulletin hispanique [En línea], 116-2 | 2014, Publicado el 01 décembre 2017, consultado el 28 juin 2022. URL: http:// journals.openedition.org/bulletinhispanique/3446 ; DOI: https://doi.org/10.4000/bulletinhispanique. 3446 


\title{
Incursiones en los Alrededores de Álvaro Pombo
}

\author{
IrÈne ANDrEs-SuÁREZ \\ Universidad de Neuchâtel
}

Ce travail analyse l'ouvre d'Alvaro Pombo, Alrededores, carrefour de différents discours, genres et formes: portraits d'écrivains et de penseurs proches de lui (Alrededor de los parecidos), récits de voyage (Alrededor del mundo), textes de caractère philosoficoessayistique (Alrededor de la gravedad) et articles de presse (Alrededor de la comicidad). Ce livre, ouvre d'un profond métissage, n'entre pas seulement en résonance avec le questionnement actuel des frontières génériques, mais offre un condensé de la poétique de l'auteur natif de Santander.

Mots-clés : Alvaro Pombo, Alrededores, métissage générique, récit de voyage, essai, billet d'humeur

Este trabajo analiza la obra de Álvaro Pombo, Alrededores, en la que se dan cita diferentes discursos, géneros y formas: retratos de escritores y pensadores afines a él (Alrededor de los parecidos), relatos de viaje (Alrededor del mundo), textos de carácter filosófico-ensayístico (Alrededor de la gravedad) y artículos periodísticos (Alrededor de la comicidad). Dicho libro, de carácter mestizo, no sólo está en consonancia con el actual cuestionamiento de las fronteras genéricas canónicas, sino que constituye todo un compendio de la poética del autor santanderino.

Palabras claves: Álvaro Pombo, Alrededores, mestizaje genérico, relato de viaje, ensayo, columna de opinión.

This paper aims at analysing Alvaro Pombo's "Alrededores", a work at the crossroads of different discourses, genres and forms: portraits of close writers and intellectuals ("Alrededor de los parecidos"), travel texts ("Alrededor del mundo"), philosophical and essayistic texts ("Alrededor de la gravedad"), press articles ("Alrededor de la comicidad"). This hybrid work does not only enlighten the present question of frontiers in literary canon genders, but also offers a concentrate of the Santander-born author's poetics.

Keywords: Alvaro Pombo, Alrededores, generic hybridation, travel story, essay, editorial press article. 
S i bien es verdad que la obra periodística del escritor santanderino, recogida $\mathcal{S}$ en buena medida en el libro Alrededores, $2002^{1}$, ocupa una posición menor respecto del resto de su producción literaria, arroja, sin embargo, mucha luz sobre su perfil humano e intelectual ${ }^{2}$, por lo que, a nuestro juicio, merece más atención que la recibida hasta el presente.

Como se sabe, la colaboración asidua en la prensa y en los medios de comunicación de masas durante el llamado período de Transición proporcionó a innumerables escritores e intelectuales la posibilidad de incrementar su notoriedad e influencia en la vida pública, llegando a convertirse incluso en personajes públicos, como se refleja en el texto humorístico de Pombo «Telepersonaje»:

Desde que entré en la tele, o mejor dicho, desde que salí en la tele, las cosas han cambiado tanto que ni siquiera tengo profesión: la gente me para en la calle y me dice: «Usted es el de la tele», o: «Usted es el de la tertulia de la tele». La frase carece ya de todo temblor interrogativo. Ya nadie duda de quién soy (...) Ser el de la tele agota todo lo que soy. Mi presencia en cualquier lugar público de Madrid provoca dos reacciones básicas: la de quienes me riñen, y la de quienes me felicitan (...) Quienes me riñen, curiosamente, siempre me excluyen de la riña a mí: me riñen por el programa, por lo que dijeron o hicieron mis compañeros de tertulia (...) Y tanto si me riñen como si me sonríen, siempre me cuentan un poco las circunstancias en las que me vieron (...). Lo curioso, en cualquier caso, de esta nueva fama mía, es su aire provinciano, su regocijo y agresión de barriada. No me consideran un ídolo, sino un vecino a disposición de todos. $^{3}$

Por esa misma época, la prensa se convirtió asimismo en un auténtico laboratorio de la literatura, en un instrumento para ensayar nuevas técnicas y formas a menudo híbridas, fronterizas, transgenéricas, que luego integrarían los autores en sus obras más extensas, lo que abrió la puerta a la configuración de nuevos géneros literarios. Así, «Desde el inicio de la democracia en 1975 y, en especial, en los años recientes -dice Alexis Ghromann-, la columna se

1. Barcelona, Anagrama. Este libro ha suscitado varias reseñas, entre otras, Ada Castells, Avui, 25 de junio de 2002, p. 39; Sergi Doria, $A B C, 13$ de junio de 2002, p. 56; Marcos Eymar, El Ciervo, noviembre de 2002, p. 42; Pilar Maurell, El Mundo, 14 de junio de 2002, p. 68; José Luis Morante, Diario de Ávila, 3 de noviembre de 2002; A. Losantos "Alrededor de la literatura», Diario de Teruel, 21 de enero de 2003; Miguel Ángel Muro, «Retratos verbales», La Rioja, 12 de febrero de 2003; Patrick Saulheimer, Hispanorama, núm. 99, febrero de 2003, p. 97. Véase asimismo el trabajo de Irene Andres-Suárez, "La obra periodística de Álvaro Pombo", en José Antonio González Fuentes y Dámaso López (eds.), La gracia irremediable. Álvaro Pombo: poéticas de un estilo, Santander, Editorial Milrazones, 2013, pp. 11-30.

2. Por ejemplo, refiriéndose a Ángel Valente comenta: «Haberse instalado en otra parte del mundo le ha vuelto vivamente marginal. Y yo, que vivo al margen, en el centro de Espańa, lo releo y le oigo siempre, cerca o lejos, con el sobresalto con que reconocemos las nítidas palabras, los silencios, de una conciencia afín (p. 90). Es decir, el escritor santanderino, mediante sus retratos, se autorretrata y, en definitiva, nosotros los lectores terminamos sabiendo más de Álvaro Pombo que de sus modelos.

3. Alrededores, op. cit., pp. 241-243. Alude a la tertulia de la televisión española en la que Pombo participó durante un año con Luis Antonio de Villena, Andrés Amorós, Jimmy Jiménez Arnau, Manu Legueniche, Lourdes Ortiz, etc. 
ha ido perfilando y emancipando como género literario en el muestrario del trabajo de varios escritores. Prueba de ello son, por ejemplo, las propias firmas de los columnistas y el creciente número de las recopilaciones que se han ido publicando ${ }^{4}$.

A este propósito, tal vez no esté de más recordar que, aunque la mezcla de artículos y relatos tiene en España un claro antecedente en la prosa costumbrista de Larra o de Mesonero Romanos, la moderna interacción entre literatura y periodismo se inspiró en el New Journalism, surgido en los Estados Unidos durante los ańos sesenta del siglo XX como consecuencia de la efervescencia política y cultural de dicho período y por el afán protagonístico de ciertos periodistas americanos que, respaldados por la industria editorial y de manera especial por el semanario The New Yorker, cuestionaron las diferencias entre el periodismo y la literatura e intentaron sacar a la novela del callejón sin salida en la que se encontraba tras el vacío dejado por los llamados escritores de la generación perdida (entre otros, Ernest Hemingway, John Dos Passos y Francis Scott Fitzgerald). Esta nueva forma de escribir, marcada por una fuerte carga de subjetividad y por una calidad estilística más propia de las piezas literarias que de los textos periodísticos, traspasó muy pronto las fronteras americanas dejando su impronta en el mundo occidental, tanto en la literatura como en la prensa. En lo que se refiere a España, el impacto se dejó sentir sobre todo en los años setenta, que es cuando se desarrolló el columnismo de opinión.

Cabe recordar que la columna es un microtexto, una composición breve en prosa, que arranca de una noticia (o de más de una) o de una idea y expresa opiniones personales del escritor (lo mismo que el editorial, aunque éste refleja obligatoriamente el punto de vista de la empresa, del periódico, no importa quién lo escriba), dentro de una extensión especificada de antemano, y normalmente con mayor pretensión «literaria» que la noticia o la crónica, de las que procede. Los estudiosos suelen hacer una distinción entre las columnas analíticas con ambición de objetividad -más habituales en el periodismo anglosajón que en el latino- y las personales, o subjetivas, llamadas comúnmente columnas de opinión, que son las que aquí nos interesan por constituir un género intermedio entre el periodismo y la literatura, cultivado por escritores reconocidos, entre los que se encuentra Álvaro Pombo.

La columna de opinión se caracteriza, en suma, por la preeminencia del yo del autor, la voluntad de estilo, la periodicidad y ubicación fijas, y la continuidad de la firma y, aunque a veces, por voluntad del autor, pase a formar parte de una colección, siempre constituye una unidad independiente, autónoma y autosuficiente. No es raro encontrar en ellas una reformulación de la noticia que cuentan -a veces la dan por conocida-, así como la integración

4. Alexis Grohmann (ed.), El género del columnismo de escritores contemporáneos (1975-2005), Madrid, Insula, núms. 703-704, julio-agosto 2005, pp. 2-3. Para el estudio de la columna, véanse también los libros siguientes: Domingo Ródenas de Moya (ed.), La crítica literaria en la prensa, Madrid, Marenostrum, 2003. Pedro de Miguel, Articulismo español contemporáneo, Madrid, Marenostrum, 2004, y Alexis Grohmann y Maarten Steenmeijer (eds.), El columnismo de escritores españoles (1975-2005), Madrid, Verbum, 2006. 
de elementos anecdóticos de la vida del escritor -algo muy frecuente en las de Pombo- o de intertextos literarios que les proporcionan hondura y proyección. Sea como sea, el columnista, según señala Antonio López Hidalgo ${ }^{5}$, ofrece cada vez menos información y va convirtiéndose en «el protagonista de sus comentarios», mediante la confesión de sus vivencias diarias, de sus filias y fobias, de su modo de reaccionar ante la realidad. Una realidad que es la suya porque prima su visión personal frente al empleo de fuentes de información. Se llega así a la sorprendente conclusión de que al columnista se le valora sobre todo por su subjetividad, que se pone en estrecha relación con la del lector, generando asentimiento o rechazo y ello es especialmente perceptible en las del escritor santanderino, las cuales poseen exactamente 37 líneas de maqueta que el autor dice escribir de un tirón, convencido de que «aquello que no puede ser dicho con precisión y claridad en treinta y siete líneas tampoco se dice con precisión y claridad en treinta y siete folios ${ }^{6}$. La mayor parte de ellas son columnas-noticia, realizadas al hilo de la actualidad, pero tampoco faltan las columnas-ensayo ${ }^{7}$, acentuadamente argumentativas, en las que reflexiona, desde una actitud ética y estética, sobre los más variados temas: históricos, políticos, filosóficos, literarios, etc. Ahora bien, el columnismo, tal como lo practica Pombo, no es estrictamente informativo, sino literario, ya que lo esencial no es ni la información ni los argumentos, sino su estilo y su voz. Él se vale de una retórica, de un estilo y de una representación específicos para comunicar lo que desea y la voz que opina, tanto si adopta la primera persona como la tercera y se disfraza de un personaje ficcional o de varios, es indefectiblemente la del autor real, como vamos a intentar demostrar mediante el análisis de algunos textos de su libro Alrededores.

Pese a que la cristalización de este volumen partió de la idea de reunir los retratos o semblanzas que el escritor santanderino había publicado semanalmente durante dos años, entre 1987 y 1989, en los faldones del suplemento cultural de Diario 16, dirigido entonces por José Miguel Ullán, el proyecto va mucho más lejos, pues recoge asimismo numerosas columnas («todos mis artículos de El Mundo tienen ese formato", declara Pombo ${ }^{8}$ ), así como los artículos periodísticos escritos entre 1975 y 1995 al hilo de la actualidad, dispersos en la prensa periódica, principalmente en El Mundo, La Tribuna y El Ciervo9.

5. A. López Hidalgo, Las columnas del periódico, Madrid, Libertarias/Prodhufi, 1996 (cito por el libro de Pedro de Miguel, Articulismo español contemporáneo. Una Antología, Madrid, Marenostrum, 2004, pp. 18-19).

6. En el prólogo a Alrededores, op. cit., p. 9.

7. Para una tipología de la columna, véase I. Andres-Suárez, "Columna de opinión, microrrelato y articuento: relaciones transgenéricas», El género del columnismo de escritores contemporáneos (1975-2005), Madrid, Ínsula, núms. 703-704, jul.-agost. 2005 (coord. Alexis Grohmann), pp. 25-28.

8. Prólogo a Alrededores, pp. 8-9.

9. Sin embargo, Pombo declara en el prólogo que muchos de los artículos redactados al hilo de la noticia y la actualidad (entre otros, los que publicó contra la Conferencia Episcopal o contra el Rector Magnífico de la Complutense...) han quedado fuera de Alrededores, p. 7. 
En su conjunto, la materia de este libro se distribuye en cuatro grandes bloques de distinta entidad genérica. El primero consta de retratos [Alrededor de los parecidos], el segundo de artículos de viaje [Alrededor del mundo], el tercero de textos de carácter filosófico-ensayístico [Alrededor de la gravedad] y el cuarto [Alrededor de la comicidad] de artículos de estilo desenfadado y humorístico, a menudo relacionados con la personalidad del propio escritor, como, por ejemplo, "Pombo Trapos», en el que describe su inclinación por la ropa («mi verdadera vocación es el trapo»), o «Telepersonaje». Nosotros centraremos nuestro estudio en los tres primeros capítulos; a nuestro entender, los más significativos.

\section{Alrededor de los Parecidos}

Mediante una técnica impresionista y el uso de la caricatura amable, Pombo nos ofrece en esta primera parte del libro alrededor de cincuenta magníficas semblanzas de escritores y pensadores con los que tiene cierta afinidad. Y, aunque no faltan las figuras extranjeras (algunos ingleses: Thomas Eliot, Iris Murdoch; italianos: Pier Poalo Pasolini; alemanes: Rilke, etc.), los retratados son, por lo general, españoles mayores que él, como José Luis Aranguren, Rafael Alberti, Antonio Buero Vallejo, Juan Benet, Carmen Martín Gaite o Jaime Gil de Biedma, o bien compañeros de lo que se llamó entonces la «nueva narrativa española»: Soledad Puértolas, Eduardo Mendoza, Félix de Azúa, Antonio Muñoz Molina, Justo Navarro, Javier Marías, Vicente Molina Foix, Rafael Chirbes, Julio Llamazares o un jovencísimo en aquel entonces, Ignacio Martínez de Pisón; entre ellos hay, además, muchos poetas, tanto españoles como extranjeros, con Pere Gimferrer al frente, y otras figuras de la vida literaria y filosófica.

Como no podía ser de otro modo, los retratos del santanderino se inscriben dentro de la tradición de la biografía y el retrato literario, que, como se sabe, se remonta a la Antigüedad grecolatina y ha adoptado a lo largo de la historia formas muy diversas. No es este el momento de trazar su evolución, por lo que nos limitaremos a mencionar algunas obras canónicas en la literatura occidental, como por ejemplo, Vies imaginaires (1896) de Marcel Schwob, quien, como Pombo, establece relaciones muy sólidas entre lo biográfico, lo histórico y lo ficcional; Suite anglaise (1927), de Julien Green; Portrait in Miniature and Other Essays (1931), de Lytton Strachey; A Quest for Corvo (1934), de A. J. A. Symons (bello ejemplo no sólo de retrato literario sino también de cómo se escribe un retrato literario) o Men in Dark Times (1968), de Hannah Arendt.

En relación con la literatura española propiamente dicha, la escritura biográfica -también el retrato- es un género híbrido que ha sido cultivado por diversos escritores ilustres, entre otros, Ramón Gómez de la Serna ${ }^{10}$, Juan GilAlbert, Rafael Cansinos Sáenz o Josep Pla y, en los últimos tiempos, parece crecer

10. Véanse entre otros, Retratos contemporáneos (1941) o Retratos completos (1968). 
exponencialmente; un buen exponente de ello es la serie de retratos literarios de Juan Marsé, Señoras y señores, publicados a lo largo del año 1976 en el semanario Por favor y recogidos después en forma de libro (1977), o los Retratos con nombre (1958-1965) (1965), de Vicente Aleixandre, aunque tal vez el más destacado de todos sea Javier Marías, quien ha explorado las más variadas modalidades de la escritura biográfica: retratos, notas biográficas, perfiles biográficos, vidas, semblanzas, retazos de vida, etc. En este sentido, son especialmente interesantes sus libros Vidas escritas $(1992 ; 2000)^{11}$ y Miramientos (1997) ${ }^{12}$; el primero está conformado por diecinueve notas biográficas de autores ingleses nacidos entre 1857 y 1912 y el segundo, que inicialmente debía titularse Contrafiguras, recoge diecisiete retratos publicados inicialmente en Cuadernos Cervantes, entre 1995 y 1997. Marías parte ahora de fotografías (extraídas a partir de cuadros, fotografías o esculturas) de escritores españoles e hispanoamericanos -entre los que se incluye él mismo- y añade un brevísimo comentario sobre el rostro y la actitud del fotografiado, soslayando indefectiblemente su vida y su obra. Para Jaqueline Heuer, «se trata, en ambos textos, de recrear las relaciones entre el artista y lo real, a través de figuras soñadas: la escritura biográfica se torna así tentativa de reconstruir lo real mediante la imaginación» ${ }^{13}$. Y, en la misma senda, podríamos situar los microtextos que publica J. J. Millás en El País Semanal, cuyo punto de partida es también una fotografía extraída de la prensa o de los medios de comunicación, en los que intenta expresar, en un tono marcadamente irónico, su propio sentir subjetivo e implicar al receptor. $\mathrm{Y}$ otros dos libros de retratos de gran interés publicados en los últimos tiempos son Gente de libro (2005), de Juan Gracia Armendáriz, en colaboración con el fotógrafo Pepe Carillo, y Póquer de ases (2009), de Manuel Vicent, que traza el perfil de una treintena de escritores universales del siglo XX.

Como Marías, Álvaro Pombo se acerca a sus fotografiados con el deseo de reconstruir lo real mediante la imaginación y teje sutiles y complejas relaciones con sus retratados, vistos todos desde su conciencia:

[...] todo narrador es siempre un artista figurativo: las primeras figuras que inventa son su propia figura, y las figuras de quienes se le asemejan, sus figuras familiares: al cabo de los ańos, todo narrador acaba sintiendo lo mismo que decía Rilke del poeta porque en una galería de retratos familiares siente que todos ellos parecen y no parecen asemejársele: se acercan y se alejan, en un continuo cambio de perspectivas, de ese yo empírico y fundacional que es el yo de cada uno de nosotros. El punto de partida de todo escritor es la primera persona del singular, el yo escribo, luego yo soy, que es intercambiable con el yo soy, luego yo escribo. ${ }^{14}$

11. Sobre este libro, $c f$. el trabajo de Francisco Gutiérrez Carvajo, «Vidas escritas, de Javier Marías», en José Romera Castillo y Francisco Gutiérrez Carvajo (eds.), Biografías literarias (19751997), Madrid, Visor, 1998, pp. 443-455.

12. Jacqueline Heuer ha dedicado un excelente trabajo a estos libros, cf. «Las narraciones "biográficas" en Javier Marías», en I. Andres-Suárez y A. Casas (ed.), Javier Marías, Madrid, Arco/Libros, 2005, pp. 243-253.

13. Ibidem, p. 253.

14. Álvaro Pombo: «figuración y desfiguración autobiográfica en las narraciones y en los poemas de Álvaro Pombo", en I. Andres-Suárez y Ana Casas (eds.), Álvaro Pombo, Madrid, Arco 
Es evidente que al escritor santanderino no le interesa la tradición canónica del retrato, así lo declara abiertamente en varias ocasiones: esto es un «noretrato", dice al trazar la semblanza de Rafael Alberti, o bien, al referirse a Antonio Gala: «Me doy cuenta de que esto no es un retrato. No es ni siquiera un perfil. Pero es, sin duda una caracterización verdadera». Él se siente atraído más bien por los escritores y pensadores que poseen una conciencia afín a la suya y manifiesta especial cariño por aquellos que han ejercido sobre él un magisterio espiritual y estético, como los poetas José Ángel Valente o Eliot ${ }^{15}$ : «Hay un texto de Valente en Material Memoria (1979) que yo siempre cito -dice- y que implica toda una teoría espiritual de la creación poética; un texto que ha sido esencial para la comprensión de mi propio yo creador» (José Ángel Valente, pp. 90-91).

En relación con su formación humanística, reivindica el magisterio de Pedro Laín Entralgo y de Aranguren; del primero recuerda con particular afecto el libro titulado Palabras menores.

Gracias a este libro, dice, y en combinación con otro de Aranguren, Crítica y meditación, entré yo en contacto con el pensamiento humanístico. Con un pensar que incluía no sólo una reflexión sobre las cosas, sino una reflexión sobre el hombre mismo y sobre uno de los lados más importantes para mí en aquellos ańos de juventud: la creación poética. (Pedro Lain Entralgo, p. 67).

Además de destacar las deudas literarias contraídas con los países de habla inglesa, Pombo nos proporciona numerosas pistas para identificar a los autores y obras determinantes en su formación literaria: «Debo decir, de antemano, que Buero, con su Historia de una escalera, ocupa en mi conciencia un lugar muy parecido al que ocupa, en la narrativa, Carmen Laforet con Nada. Ambas obras (...) fueron intensamente actuales y significativas en una desordenada cabeza juvenil» (Antonio Buero Vallejo, p. 27).

Consciente de que a los hombres se les conoce por lo que han escrito, Pombo indaga en los libros de sus retratados en busca de su alma y también de un par de citas que condensen la esencia de su obra. A menudo, alude a un libro específico del retratado que lo ha marcado por alguna razón y reproduce un fragmento en prosa o un poema entero si se trata de un poeta (admira especialmente a Rilke, Eliot, Aleixandre y Cernuda) y los comenta con gran agudeza y profundidad ${ }^{16}$.

Libros, Col. «Cuadernos de Narrativa», 2007. Primer volumen monográfico consagrado a la obra del escritor santanderino, aunque en diciembre de 2001 la revista barcelonesa Quimera le había dedicado un número especial, el 209 (Los cielos rasos de Álvaro Pombo), coordinado por Domingo Ródenas de Moya.

15. «Eliot conduce a la tradición de la espiritualidad occidental, cristiana, uno de cuyos maestros es San Juan de la Cruz. Es un escritor sencillo, dotado de inmensa complejidad espiritual». Para Pombo, la «naturalidad y sencillez» del lenguaje de Eliot es sobresaliente, pues «llegó a expresar estados de conciencia sumamente complejos» (p. 32).

16. Lo interesante de García Montero es que, a la vez, canta apasionadamente el amor y sabe que «raras veces resisten / dos soledades juntas las palabras». Excelente poema, veraz como una instantánea, el que empieza: «Bajo una lluvia fría de polígono...» ¿En qué acabará Luis García Montero, este ángel enamorado, irónico y sabio? No lo sé. Pero me da buena espina el siguiente 
Así, por ejemplo, refiriéndose a C. Martín Gaite, señala:

Hojeo su único libro de poemas, titulado $A$ rachas, que leí, lo confieso, con excesiva precipitación hace años (...). Es un notable autorretrato de la vida y la muerte propia de esta narradora de la vida interior, una sensibilidad desplegada entre visillos, en el cuarto de atrás, en fragmentos de interior que escribió sin embargo: "Quiero huir de los ámbitos / calientes y tapiados / salir sin compañía / por el mundo adelante». Expresó ese deseo en su incansable búsqueda de interlocutores. (Carmen Martín Gaite: Obituario, pp. 147-48).

Otras veces pone el énfasis en la presentación de ciertos recursos literarios predominantes: «Desde el punto de vista del modo de contar, (...) Luis Mateo Díez (...) tiene dos voces: una alambicada, que yo -frunciendo el ceñollamaría literaria, y otra llana e incesante que lo enreda todo en un larguísimo relato donde todo se trama y en cuyo entramado, como pajarillos, como moscas, caemos por igual amigos y enemigos...» (p. 125). Gusta de rememorar también el momento y la situación en que conoció a su retratado y, aunque no rehúye el retrato físico ${ }^{17}$, da la preeminencia al retrato moral e intelectual:

(...) sin conocerle en realidad, sin haber hablado nunca con él, a fuerza sólo de ver representaciones de sus obras y de «leerlas» (porque mi generación leyó mucho más teatro del que llegaba a representarse) he llegado a imaginar que sé como es: es hombre seco, poco comunicativo, un tanto obstinado -quizá muy obstinado-, que dice la verdad. (Antonio Buero Vallejo, p. 27).

Esta es claramente una biografía imaginada, ficcional, aunque eso sí, fundamentada en la escritura y en el talante del retratado. Otras semblanzas son, en cambio, particularmente impresionistas, pues en ellas prima el carácter subjetivo y plástico o la valoración estética, según pone de manifiesto la que dedica a Rafael Alberti, inmovilizado a causa de una fractura:

Maniatado, patiatado y guasón y recitando a Góngora le tuve encarcelado casi una hora y media en la comisaría miope de mis ojos. Blusa azul pintarrajeada y zapatillas, según creo de charol muy negro y muy brillante. Tuve la sensación al entrar de que el sillón entero y Rafael de pie encima eran una montańa florecida frente al mar que

y valiente texto en prosa, de Diario cómplice, que recuerda la energía de los Adagia de Wallace Stevens, y que dice así: «No hay discrepancias enigmáticas entre la realidad y la imaginación. Existe una realidad imaginaria, un modo fabulado donde se juntan las historias y la historia, los poemas y la poesía, su soledad y los que estamos solos». Sólo pueden afirmar esto -y de hecho sólo lo afirman- los grandes poetas puros y los grandes románticos (es obvio que me estoy refiriendo a Hegel). Y sí, Luis García Montero, recuerdo «que tú existes tan sólo en este libro». Es un espléndido libro. Existir ahí y así es existir con creces» (Luis García Montero, p. 48).

17. «Su cara de aguilucho, su aire alto y dramático, tan clásicamente español, ha acabado por volverse inglés: Masoliver es ya un puro excéntrico -una especialidad de aquellas islas- que acude a los pubs precisamente para no comunicarse con el prójimo» (J. A. Masoliver, p. 82).

«La cara redonda, los negros ojos brillantes y sensuales, la boca grande que sonríe y que ríe con todos los dientes blancos, muy iguales, como almendras pequeñas. Nariz fenicia, curva, un poco móvil, como la nariz de un hijo de jeque petrolero que estudia y liga en Oxford» (Vicente Molina Foix, p. 73). 
atardece allá en la Castellana. Y tenía Alberti, digo, el azul estático (...) «nostalgia / de haber sido azul puro en movimiento». De haber sido y de serlo, ¡qué diablos de El Bosco!, aquí nadie se muere, en su presencia imantada (...).

Se puede "comprobar» Sobre los ángeles, me dijo, "cosa por cosa, palabra por palabra». Por remota y difícil que parezca, la poesía dice la realidad y la verdad. Rafael Alberti es la sabiduría de todas las imágenes del mundo. Era hora de marcharse (Ahora que se había quedado momentáneamente paticojo, Alberti tiene una campanilla de altar para llamar a los niños). Yo salía. La campanilla anunció a toda la casa que, por fin, plúmbeo y pombo, me hundía para siempre en la dársena. Me sentí deslumbrado, agradecido, Rafael, que anunciaras a campanillazos que voy llegando un poco al fondo de tu mar. (Rafael Alberti, pp. 19-20)

Como consecuencia de esta tendencia espiritualista e intimista de tipo intuitivo, Pombo nos ofrece aquí un mundo emocional y sensorial muy rico y, en otras ocasiones, conjuga el impresionismo con los juegos lingüísticos y fonéticos:

García, en su soledad de ge pura y simple, tiene algo de fricativo y sordo, como el saltamontes, o de oclusivo, inicial y absoluto, precedido por su juventud y seguido de su $a$, como el gato. He aquí, a continuación, un ejemplo de Álvaro García como fricativo y sordo: «Me acuerdo de la hora en que mis padres / llamaban y yo estaba poco explícito / por la ligera otitis». He aquí, en «Definición del frío», un ejemplo de Álvaro García como saltamontes: «Todos tienen carrera y todos están tristes». He aquí como gato (de uno de sus libros titulado precisamente Cuatro gatos): «La noche de diciembre no alargaba / demasiado su cuello, pero la luz vigía / de la luna en los muros vio que íbamos / cuatro gatos bebidos y acordándonos " (Álvaro García, p. 49).

Y ese carácter lúdico y humorístico se intensifica en el retrato consagrado a Fanny Rubio:

Fanny Rubio no me quiere. ¿¿Me quiere? No me quiere. No me manda sus poesías. No me saca en sus Antologías. No me relee en los tranvías y, por último no me convida a merendar chocolate con churros en su casa, que lo hacen riquísimo las niñas doctorandas, en chocolateritas de cobre. Hay algo infantil y melancólico en esa Fanny Rubio, peinada a la diabla... (Fanny Rubio, p. 126).

Es evidente que en todos estos textos prevalece la perspectiva de Pombo, pues, además de recurrir constantemente a la primera persona gramatical, son numerosos los detalles, conscientes o inconscientes, que transmiten con mucha distancia y, a veces, humor sus propias inclinaciones, su personalidad reflexiva e histriónica, así como su visión del mundo y de su poética. No en vano, los textos de este bloque están salpicados de constantes reflexiones metaficcionales, tanto literarias como metafísicas, puestas en boca de ese yo narrativo al que nos acabamos de referir. En relación con las literarias, abundan los comentarios sobre la creación poética (p. 67) y sobre el acto de crear: «... crear no es un acto de poder -poder y creación se niegan-; es un acto de aceptación o reconocimiento. Crear lleva el signo de la feminidad (...) Crear es generar un estado de posibilidad, en la que la primera cosa creada es el vacío» (José Ángel Valente, pp. 90-91). 
También son frecuentes los comentarios sobre la entidad del poeta («Para ser poeta no basta -ni con mucho- ser esteta. Hay que hacerse con la verdad», Ángel González, p. 52), la lectura y el lector (P. Laín Entralgo, p. 67) o sobre los rasgos singularizadores del texto literario teatral (A. Buero Vallejo). Y resulta particularmente interesante lo que dice sobre el aprendizaje del oficio de escritor:

(...) los auténticos maestros literarios fueron aquellos oscuros profesores y curas sin rostro y sin nombre que daban clases de literatura en bachillerato: ahí se aprende a escribir. Ahí se aprenden todos los trucos, trampas, malicias, miserias y grandezas del oficio; ahí, en bachillerato. Y todo lo demás -lo poco que falta- se roba y se imita. La grandeza consiste en imitar, robar y piratear con tal intensidad, continuidad y perfección que el primero en aplaudir sea el robado. La tradición es lo que se imita y se roba.... (T. S. Eliot, pp. 31-32)

Consciente de que la objetividad es una quimera, Pombo deja espacio en sus retratos a la arbitrariedad, a lo fantástico y a lo onírico, para que aflore lo sentimental y lo emocional, todo aquello que la biografía canónica stricto sensu no lograba transmitir. Además, y esto es tal vez aún más importante, mediante sus semblanzas, fruto del entrecruzamiento entre lo biográfico histórico y lo universal literario, se autorretrata como hicieron antes que él Juan Ramón Jiménez en Españoles de tres mundos (1942), o Vicente Aleixandre en Los Encuentros (1963) y, en cierta manera, es lo que hace también en sus relatos de viajes.

\section{Alrededor Del MUndo}

La segunda parte del libro incluye textos firmados entre septiembre de 1975 y mayo de 1988 y remite a viajes efectuados por Álvaro Pombo a distintos lugares de Inglaterra y del mundo (México, Lisboa, Berlín, las Islas Baleares, etc., de los que dio cuenta en El Mundo, La Tribuna y El Ciervo), emprendidos con una voluntad literaria y no turística, y respondiendo a una triple intencionalidad: documental, metafísica y estética. Como ha demostrado Geneviève Champeau ${ }^{18}$, el relato de viajes es un género multifacético y heteróclito que pone en escena un vasto abanico de géneros literarios y no-literarios, así como formas escriturales de muy diversa índole y los del santanderino no escapan a esta regla, aunque lo mejor de sus piezas tal vez sea la figura de ese viajero-narrador (trasunto de Pombo) sorprendido por lo que va viendo: nos hace entrar de lleno en los paisajes o ciudades que describe, recorrer los mismos espacios, impregnarnos de su ambiente, sentir en nuestra propia piel el efecto del clima, por ejemplo, la humedad o la niebla de Londres en el otoño; y son muy abundantes también

18. Cf. Geneviève Champeau, «El relato de viaje, un género fronterizo», en G. Champeau (ed.), Relatos de viajes contemporáneos por España y Portugal, Madrid, Verbum, 2004, pp. 15-31. Véase asimismo el imprescindible trabajo de Luis Lopéz Molina: «Hacia un perfil genérico de los libros de viajes», en G. Champeau (ed.), Relatos de viajes, op. cit., pp. 32-43. 
las informaciones relativas a su personalidad: «soy cauteloso y soy sumamente sedentario, apenas viajo» (Resfrecar la memoria), "Yo soy, por temperamento y también por elección, un estable» (Ternura solitaria); y, en Un viaje a Lisboa, agrega: «Creo que he logrado en estos días de mi viaje portugués distanciarme un poco de mí mismo. Me he cansado mucho andando porque estoy muy gordo. Ceno opíparamente el martes por la noche en el Escorial. Genio y figura hasta la sepultura, desgraciadamente» (p. 161).

Nuestro viajero está dotado de una gran sensibilidad artística que lo lleva a vivir emociones muy profundas, como, por ejemplo, el placer que experimenta al escuchar en una basílica abandonada de Hampstead, un pueblecito inglés de finales del XVII, lo que denomina el «ejercicio de dedos» de un joven músico que se entrena para dar un concierto (Sentarse a escuchar) o, en otro registro, el desasosiego que le proporciona la visita al muro de Brandenburgo o a la Postdamer Platz:

Me ha impresionado el muro. Y he subido a varias de esas como tribunas donde los turistas se suben para observar «el otro lado». He llegado hasta lo que fue aquella bellísima Postdamer Platz. He recorrido el solar de lo que fue la Gestapo (...). Sé que son lugares terribles para los alemanes contemporáneos y mi memoria colectiva tiembla ante ellos. (Ternura solitaria, p. 169).

Viajando, aspira a liberarse de lo cotidiano y rutinario, pero también a encontrase consigo mismo, explorar su propio ser y conocerse mejor; en una palabra, invita a sus lectores a vivir, mediante la lectura, algo de lo que él ha vivido, a compartir una experiencia enriquecedora porque, según López Molina,

(...) el relato de viajes, al igual que la autobiografía, incorpora la subjetividad de su autor, se hace eco de su sensibilidad, de su ideología, y el relato termina convirtiéndose en un lugar de encuentro de un territorio, una subjetividad y una escritura (...), el autor actúa como filtro de la experiencia vivida y del componente informativo de su obra, escribe lo que sabe y lo que ha vivido, fundiendo ambas cosas en una experiencia compleja que «textualiza» a posteriori. ${ }^{19}$

Pombo no se limita a levantar acta de lo que ve y siente, sino que lo hace objeto de una reflexión historicista, moralizadora a veces, o metafísica ${ }^{20}$; no en vano, manifiesta una fuerte aversión hacia los turistas poco respetuosos con el patrimonio cultural, a los que califica de "horteras» y "mortales», en el sentido de burdos e insufribles, que «malentienden» los desnudos y "malmiran» los museos» (Rollerball), y muestra una clara propensión por los conceptos relacionados con el mundo del viaje $\mathrm{e}^{21}$ :

19. Ibidem, p. 36.

20. Por lo general, el viajero literario sabe bien por qué va a un sitio y no a otro y persigue un doble placer: el estético (la belleza de lo natural y de la obra humana) e intelectual (el conocimiento de tierras, de personas, de modos de vida, de huellas de la historia, etc.). Su experiencia viajera es personal e intransferible.

21. Viajar incita a recordar, la evocación del viaje es inseparable del recuerdo, aunque no se 
Viajar es muy difícil -dice-, tan difícil como leer bien un libro, o quizás más todavía. Uno se amilana con la novedad posible, lo inesperado posible, y lo transforma todo en sosa expectación de cosas consabidas. Para viajar hay que pasar por la gran tarea fenomenológica de la desrealización del propio yo asustado. Por eso todo el mundo se traslada de un lado a otro hoy día; pero muy pocos viajan. (Un viaje a Lisboa, p. 160).

Viajar es convertirse en afluente de la propia conciencia (Viva México, p. 157).

Nuestro viajero descalifica el avión como medio de locomoción porque «elimina lo discursivo del viaje, lo asenderado, para reducirlo todo a instantáneas: gloria y miseria de viajar en avión» (Viaje a Calvià, p. 162). Y, en Privilegio de andar descalzos, lleva a cabo una reflexión metafísica y sociológica sobre la idea de las vacaciones pagadas, una de las grandes reivindicaciones sociales de nuestro siglo regido por los conceptos de tiempo libre y de ocio, y opone las vacaciones en la montaña a las de la playa como dos formas antagónicas de concebir el descanso y hasta la existencia. Para él, la montaña y el río conllevan la idea de esfuerzo, la playa no; ésta representa el «descanso puro, una ensońación solar. Vital de horizontalidad perfecta, descansado, descalzado y tumbado» (p. 172); es decir, encarna el mito del placer y de la libertad absolutas, lo que lo conduce a deplorar que ciertos lugares paradisíacos del planeta, como las islas Baleares, sean literalmente invadidos por los turistas con sus devastadoras consecuencias para el paisaje y la vida de los autóctonos.

En ciertos casos, sigue deliberadamente la senda de escritores o de artistas que hicieron antes que él el mismo recorrido (en Viaje a Calvià menciona a Chopin y a George Sand), en cuyo caso, no desaprovecha ninguna ocasión para tejer lazos intertextuales con las obras de aquéllos. Así, en Lisboa, exclama al llegar la noche: «¡Cuánto se dulcifica Lisboa al atardecer!» y transcribe un poema de Chiado, poeta portugués del s. XVI: Vem noite antiquísima e idéntica / Noite rainha nacida destronada / franjada de lentejoulas azuis...» (...). Y agrega:

Las sombras lentamente nos sobrecogen sentados en una terraza contigua a A Brasileira do Chiado, muy pessoana. Mi acompañante me cuenta que recorrían antaño estas calles los personajes y los enamorados de Eça de Queiroz (...). Pensando en la noche leo Sombras en Lisboa, de un poeta anónimo, escrito en la pared de la librería Bertrand: "Nas ruas desta cidade / ao anoitecer / há tal saturnidade / há tal melancolia». Saturnidade es una palabra enigmática y muy bella. Designa la oscuridad, la lobreguez, si se quiere. Pero se trata de una negrura exaltada, una fiebre saturnal y erótica que recorre todo el Chiado como un viento romántico. (Un viaje a Lisboa, p. 161)

Aunque tal vez el texto más literario de este bloque sea el consagrado a la ciudad de Londres, que nos presenta desrealizada por la niebla en el mes de noviembre:

Londres es una ciudad imaginaria. O fantasmal, si no se quiere exagerar, con cremaciones brujeriles, infantiles, de efigies de Guy Fawkes el 5 de noviembre. O sinuosa y detectivesca, como todo el mundo sabe. Mortal, en cualquier caso, si uno se descuida y cuela por uno de sus innumerables huecos y vacíos (lo menos mortal de

agote en él (Refrescar la memoria). 
todo ahora mismo son las bombas de IRA, que uno encuentra a cada paso). Lo más mortal de todo es la oquedad de Londres o sus postrimerías de octubre y novísimos de noviembre. Ahora la frontera de lo real y de lo irreal se borra a ratos. Transparente falta de claridad -que casi es maldad-. Como la ironía, la lejanía, el amor. (Niebla, amor y libras, p. 156)

Todo lo dicho hasta aquí no nos debe hacer olvidar, sin embargo, otro de los propósitos del viajero: conocer tierras y personas y contarlo luego a otros sin omitir la realidad social y humana en la que están inmersos; así por ejemplo, en el texto Rollerball, se alude a un recorrido efectuado por esta ciudad en plena psicosis terrorista de IRA y se elogia a la policía británica por «evitar que el fanatismo, la confusión y el odio nos vuelvan locos a todos», y concluye con una frase de un trabajo de Lorenzo Gomis publicado en la revista El Ciervo («Treinta años, treinta siglos»): "La violencia es un misterio de soledad humana, de humana impotencia, de deseos que tratan de imponerse a la realidad» (p. 153).

\section{Alrededor de la Gravedad}

Pese a que Pombo no es un filósofo, tiene una formación filosófica muy sólida, pues se licenció en Filosofía por la Universidad Complutense de Madrid $\mathrm{y}$ es Bachelor of Arts (en filosofía igualmente) del prestigioso Birkbeck College de Londres, lo que explica que en toda su obra subyazca un diálogo profundo con una buena parte de la tradición filosófica occidental.

Según la opinión de varios estudiosos, la mayor originalidad de su narrativa estriba precisamente en la adaptación de la filosofía a la conciencia de unos personajes que piensan, y el ajustar su estilo al movimiento del fraseo argumentativo propio de la filosofía. Es decir, su obra de ficción invita a una actitud filosófica, pese a que, como indica Juan Antonio Masoliver Ródenas, «en Pombo no hay un sistema filosófico sino una respuesta filosófica ante los datos de la conciencia y la experiencia (...) y tampoco hay un sistema estético pero sí reacciones estéticas. Lo ético, lo estético y lo reflexivo, al igual que lo lírico, aparecen como punto de la trama» ${ }^{22}$. Por su parte, Marcos Eymar Benedicto abunda en la misma dirección al afirmar que en la obra de Pombo se da una asimilación tácita de la filosofía que pasa por el empleo de recursos formales o conceptuales tomados directamente de los textos filosóficos ${ }^{23}$.

Sea como sea, en los artículos y columnas filosóficos que componen estos Alrededores, se percibe una fuerte coloración filosófica ${ }^{24}$ materializada en la

22. J. A. Masoliver Ródenas, «Agonía y resurrección de la novela», en Quimera, núm. 209, diciembre de 2001, p. 23.

23. Cf. «Crítica de la razón impura. La utilización literaria de la filosofía en la narrativa de Álvaro Pombo", en I. Andres-Suárez y A. Casas (eds.), Álvaro Pombo, op. cit., pp. 133-149.

24. En el prólogo a Cuentos reciclados, nos dice: «De la filosofía, sin el más mínimo remordimiento y miramiento, robé siempre su color y siempre que pude -como hizo Eliot con Bradley- he apresado y saqueado y robado el poderoso ritmo, el gusto formidable de la prosa, de la elocuencia, de los grandes filósofos», Barcelona, Anagrama, 1997, p. 9. 
figura de un narrador proclive a las especulaciones, a los discursos reflexivos, y a la indagación y discusión sobre la naturaleza de ciertas palabras o conceptos, como la muerte ( San Isidro Labrador»), el amor («El amor: un proyecto posible»), la soledad («La soledad en abril»), la imaginación («Imaginación y monotonía»), la paz y la guerra («El interior de la paz»), el perdón («El problema del perdón»), la justicia («La opinión pública y el juicio del juez»), la Patria («El sentimiento patriótico) o la posibilidad y la imposibilidad («Vivencia del callejón sin salida»). Como botón de muestra, transcribimos una de las columnas más logradas de este apartado sobre el tema de la soledad:

Cada año, por estas fechas, las ciudades, con la primavera urbana, se vuelven brillantemente solitarias. Abril es el mes de encontrarse con la soledad objetivada en las cosas del mundo. Buen momento para preguntarse si la soledad es sólo un sentimiento de soledad o si es, ante todo, una situación objetiva. El diccionario de la RAE dice: sustantivo femenino; carencia voluntaria o involuntaria de compañía. Es fácil asimilar esta definición nominal a la definición existencial que propone, por ejemplo, Heidegger. Para este filósofo «el ser-solo es un modo deficiente del ser-con, su posibilidad es la prueba de la realidad del último». Tiene razón Heidegger y quizá esta manera sucinta de expresar la soledad sea la más cruel de todas: el encontrarse solo se define a partir del encontrarse acompañado pero como una deficiencia o falta de compañía. Quiere decirse que los seres humanos nos encontramos radicalmente en compañía y que la soledad es una situación objetiva en la que también nos encontramos pero por defecto. Es, creo yo, interesante hacer ver que no habría concepto de soledad si no hubiera en cada uno de nosotros el radical estar con todos los demás. La soledad es penosa porque incluye ese estar con los demás también cuando no se está con ellos, cuando se está solo. La expresión carcelaria anglosajona solitary confinement-una forma especialmente insufrible de castigo- incluye una interesante relación al fin: confinar es delimitar al ser que está radicalmente con los demás a estar solo. El hecho de que pueda ser una forma de castigo revela que no se trata de un sentimiento, sino de una situación efectiva que afecta a todo el ser solitario: es curioso que la RAE incluya en esa carencia de compañía en que la soledad consiste, dos posibilidades: carencia voluntaria y carencia involuntaria. La carencia voluntaria no parece ser del todo soledad puesto que podría remediarse suprimiéndola. Es en la carencia involuntaria, radical, la que afecta a los ancianos y a los niños pequeños - por absurdo que parezca-, a los moribundos, donde vemos con toda su destructora energía la positividad de esa falta de ser en que consiste encontrarse involuntariamente solo en el mundo. («La soledad en abril», publicado por primera vez en El Mundo, 8 de abril de 1995).

Antes de ofrecernos su propia percepción de la soledad, así como sus devastadoras consecuencias en la sociedad actual, propósito esencial del texto, Pombo presenta el concepto de «soledad» a la luz de parámetros lingüísticos (expone la definición que aporta el diccionario de la Real Academia) y filosóficos (parte de la definición existencial heideggeriana, que estipula que «el ser-solo es un modo deficiente del ser-con»), y especula sobre si la soledad es un sentimiento, como parece indicar el diccionario de la RAE, o una situación, ya sea objetiva o subjetiva. Al final, apoyándose en el significado de la expresión anglosajona solitary confinement, opta por desautorizar la posición de la Academia («el hecho de que pueda ser una forma de castigo revela que no se trata de un sentimiento sino de una situación efectiva que afecta a todo el ser 
del solitario») e imponer su visión personal en detrimento de las otras fuentes de información utilizadas.

En otros casos, son los sentimientos los que se convierten en el eje del debate y de la reflexión («El amor: un proyecto posible», «El arrepentimiento y la desesperación»), o bien la propia práctica literaria y sus verdades. En relación con esto, otro texto interesante es el titulado «De las narraciones y sus filosofías furtivas", publicado por primera vez en enero de 1985 en la Revista de Occidente ${ }^{25}$. En él, Pombo presenta el robo prometeico de la filosofía llevado a cabo por los novelistas en estos términos: «La novela es un género híbrido y gran parte de su encanto proviene del carácter aluvial de sus materiales. No hay nada que a un novelista no le venga bien» (p. 226) y, como «los novelistas son desaprensivos», reducen la filosofía a objeto cultural y la utilizan como algo capaz de conferir al texto literario una «impresión de profundidad» (p. 230). En este sentido, cabe recordar que el mismo Pombo confiesa en el artículo que nos ocupa sentirse más interesado por los proyectos filosóficos que por los sistemas filosóficos y preferir la filosofía por su relación con la elocuencia que por su relación con la verdad (p. 225).

Siguiendo libremente la argumentación de Pombo en el citado artículo, Marcos Eymar Benedicto ${ }^{26}$ destaca cuatro niveles en su asimilación literaria de la filosofía: el ornamental, el formal, el epistemológico, y el crítico, y viene a decir lo siguiente: el autor santanderino emplea la filosofía como aderezo culturalista, como un instrumento para brillar y seducir al lector, y antes que una fuente de temas y motivos, la filosofía es para él un estilo ${ }^{27}$, pues muestra una fuerte propensión a conjugar términos y expresiones inequívocamente filosóficos («ser-en-el-mundo», "pre-comprensión», «Libertad trascendental»...) con otros ostensiblemente coloquiales, situados en las antípodas del conocimiento filosófico.

Pombo manifiesta su convencimiento de que, en la actualidad, la novela es superior a la filosofía a causa del "carácter aluvial de sus materiales» (p. 226) y de su capacidad de integrar el pensamiento filosófico en una unidad totalizadora. Como M. de Unamuno y $\mathrm{M}^{\mathrm{a}}$ Zambrano, parece pensar también que la filosofía española está subsumida en la literatura y no encorsetada en parámetros filosóficos ${ }^{28}$, y una prueba fehaciente de ello es su producción narrativa, aunque tampoco hay que desdeñar sus artículos, en los que las interrogaciones filosóficas se convierten en materia ensayística.

Para concluir, diremos que el periodismo tal como lo practica Pombo es mucho menos informativo que literario, filosófico o ensayístico, puesto

25. Cf. Thierry Nallet, «Polifacetismo de la novela de Álvaro Pombo», en I. Andres-Suárez y A. Casas (eds.), Álvaro Pombo, op. cit., pp. 91-110.

26. Marcos Eymar Benedicto, "Crítica de la razón impura. La utilización literaria de la filosofía en la narrativa de Álvaro Pombo", en I. Andres-Suárez y A. Casas, Álvaro Pombo, op. cit., pp. 133-150.

27. Ibidem, p. 142.

28. Miguel de Unamuno, Del sentimiento trágico de la vida (1913), Madrid, Espasa-Calpe, 1976, p. 304. 
que tanto sus columnas como sus artículos no se sustentan tanto en la documentación y en los argumentos, cuanto en su estilo. En ellos la realidad y la ficción se interrelacionan constantemente y desbordan alegremente los cánones genéricos a los que supuestamente pertenecen; con todo, el santanderino no rehúye la realidad inmediata, la actualidad espańola, inglesa y mundial, o los problemas de sus conciudadanos como, por ejemplo, la Guerra del Golfo, el terrorismo de IRA, el uso de las anfetaminas, la relación de la juventud con la prensa, la violencia, la corrupción, la política, la religión y el sentimiento de la culpa, la liberación de la culpa, etc. Por aparecer en la prensa, los textos de este volumen pueden considerarse artículos de opinión, pero, por los procedimientos retóricos y los motivos utilizados, están mucho más cerca de los textos literarios. En cualquier caso, Pombo ha sabido conjugar y ensamblar en este libro la más elevada especulación filosófica con el coloquialismo más certero, lo más profundo y lo más cotidiano, lo trágico y lo cómico. Y, como en sus novelas y cuentos, despliega también aquí sus mejores armas: el talento para captar la vida cotidiana, la fina ironía y el sentido del humor y una prosa ágil y deslumbrante que nos atrapa y cautiva, armas, en suma, que lo han convertido en uno de los escritores más originales y sagaces de la literatura española contemporánea.

\section{Bibliografía}

Andres-Suárez Irene, "Columna de opinión, microrrelato y articuento: relaciones transgenéricas", El género del columnismo de escritores contemporáneos (1975-2005), Madrid, Ínsula, núms. 703-704, jul.-agost. 2005 (coord. Alexis Grohmann), pp. 2528.

Andres-Suárez Irene y Ana Casas (eds.), Álvaro Pombo, Madrid, Arco Libros, Col. "Cuadernos de Narrativa», 2007.

Arnas Mur Susana, El arte del retrato y de la biografía en Ramón Gómez de la Serna, Universidad de Zaragoza, Prensas de la Universidad, 2001 (tesis doctoral).

Champeau Geneviève (ed.), Relatos de viajes contemporáneos por España y Portugal, Madrid, Verbum, 2004.

— «El relato de viaje, un género fronterizo », en G. Champeau (ed.), Relatos de viajes contemporáneos..., op. cit., pp. 15-31.

Eymar Benedicto Marco, "Conversaciones. Álvaro Pombo », El Ciervo, núms. 605606, agost.-sept. de 2001, pp. 26-28.

- «Crítica de la razón impura. La utilización literaria de la filosofía en la narrativa de Álvaro Pombo», en I. Andres-Suárez y A. Casas (eds.), Álvaro Pombo, op. cit., pp. 133-149.

Grohman Alexis (ed.), El género del columnismo de escritores contemporáneos (19752005), Madrid, Ínsula, núms. 703-704, julio-agosto 2005.

Grohman Alexis y Maarten Steemeijer (eds.), El columnismo de escritores españoles (1975-2005), Madrid, Verbum, 2006.

López Molina Luis, « Hacia un perfil genérico de los libros de viajes », en G. Champeau (ed.), Relatos de viajes contemporáneos..., op. cit., pp. 32-43.

Miguel Pedro de, Articulismo español contemporáneo, Madrid, Marenostrum, 2004. 
Masoliver Ródenas Juan Antonio, «Agonía y resurrección de la novela», en Quimera, núm. 209, diciembre de 2001, pp. 19-23. Reproducido en Voces contemporáneas, Barcelona, El Acantilado, 2004, pp. 275-290.

— «Trascendencia y humorismo en el último Pombo», en I. Andres-Suárez y A. Casas (eds.), Álvaro Pombo, op. cit., pp. 61-89.

Nallet Thierry, "Polifacetismo de la novela de Álvaro Pombo», en I. Andres-Suárez y A. Casas (eds.), Álvaro Pombo, op. cit., pp. 91-110.

Ródenas de Moya Domingo (coord.), Los cielos rasos de Álvaro Pombo, Barcelona, Quimera, núm. 209, diciembre de 2001.

Ródenas de Moya Domingo, "Álvaro Pombo. Una ética del cuidado», Quimera. Los cielos rasos..., op. cit., pp. 11-18.

Ródenas de Moya Domingo (ed.), La crítica literaria en la prensa, Madrid, Marenostrum, 2003. 